\title{
Effect of the Anolyte ANK-SUPER detergent agent on the vegetative microflora
}

\author{
D.A. Bannikova*, P.A. Popov
}

All-Russian Research Institute of Veterinary Sanitation, Hygiene and Ecology - Federal Scientific Center All-Russian Research Institute of Experimental Veterinary Medicine named after K.I. Scriabin and Ya.R. Kovalenko of the Russian Academy of Sciences, Moscow, 123022, Russia

\begin{abstract}
Nowadays the provision of the safety of food products for human health, including of animal origin, is extremely important in the world. Since 2007, the Russian Federation has been monitoring the safety of food and feed in order to protect public health, assess the veterinary safety of imported and domestic food raw materials, products of its processing and feed, as well as to develop measures to prevent the entry of dangerous veterinary products into the market in relation to products of animal origin and feed. One of the main factors in production of high sanitary quality is compliance with the high sanitary level of their production, storage and sale. In this regard, it is necessary to pay attention to the choice of disinfectants. They must meet the following requirement and have such properties as a wide range of disinfecting action; detergency property and minimal corrosiveness. In addition they must effectively destroy bacteria, viruses, fungi and spore, be safe for humans, animals and the environment and be as simple as possible in use and relatively inexpensive. In Russia, the use of more than 400 chemicals of domestic and foreign production is allowed and their number is constantly growing. The agents used for disinfection, such as formaldehyde, QAC, aldehydes, etc., are highly volatile, toxic and environmentally unfriendly. The development of new disinfectants is mainly connected with the creation of new compositions of chemical agents, which increases their cost.
\end{abstract}

\section{Introduction}

During the choice of modern disinfectants, it is necessary to take into account a number of their properties and features, namely: antimicrobial activity against microorganisms of four resistance groups, toxic effects on humans and animals, effects on treated surfaces, conditions, shelf life and concentration stability during storage, ease of use, as well as the possibility of the use of various devices and equipment, the impact on the environment [4-15].

Studying the structural and functional changes in bacterial populations under the influence of various abiotic factors, the authors payed attention to the reports on the bactericidal properties of electrochemically activated (ECA) solutions, in particular, neutral anolyte (ANK) [5, 7]. Anolyte is a solution with ultra-high electron-withdrawing activity, acting on lipid membranes, cell organelles and intracellular molecular complexes.

The main disadvantages of ANK during 2001-2005 were successfully eliminated by the efforts of specialists and scientists from the Institute of Electrochemical Systems and Technologies named after Vitold Bakhir. As a result, the technical solutions were found that formed the basis for a number of STEL installations of the new (third) generation [13, 14].
V. Bakhir created a STEL-M type unit, which allows the production of ANK according to a new technological scheme. ANK, obtained in STEL-M devices, is characterized by low mineralization (total content of dissolved inorganic electrolytes) at an increased concentration of a metastable mixture of chlorineoxygen and hydroperoxide oxidants [5-7]. In particular, if ANK produced in installations of the "STEL-10N120-01" type, with a concentration of oxidants from 200 to $500 \mathrm{mg} / \mathrm{l}$, has a mineralization of 2 to $5 \mathrm{~g} / \mathrm{l}$, then the units of ANK of the "STEL-M" type has a mineralization of 0.5 to $2.0 \mathrm{~g} / 1$ with the same limits of change in the concentration of oxidants.

Low mineralization of ANK provides its reduced corrosive activity with a simultaneous increase in antimicrobial properties, which is explained by a more intense osmotic transfer of active substances into the internal environment of microorganisms. In addition, ANK obtained in STEL-ANK devices retains antimicrobial activity for a longer period (up to 7 days), which is associated with improved purification of the initial solution from heavy metal ions during the synthesis of ANK in an installation of the STEL-M type. The next step towards the improvement of ANK was the creation of a STEL-ANK-PRO unit, which allows the production of ANK with a mineralization of no more

* Corresponding author: vniivshe@mail.ru 
than $1 \mathrm{~g} / \mathrm{l}$ at a concentration of oxidants of at least 500 $\mathrm{mg} / 1[2.4]$.

The researchers from Institute of Electrochemical Systems and Technologies named after Vitold Bakhir developed a technology to obtain a universal (disinfection, pre-sterilization cleaning, sterilization) electrochemically activated solution - "anolyte ALOKS", which is produced by the introduction of acetic acid in the amount of 1 vol. \% into ANK with a concentration of oxidants of $500 \mathrm{mg} / 1$, synthesized in devices such as STEL-M (and only in installations of this type). Active substances of "anolyte ALOKS" are a mixture of metastable inorganic (chlorine-oxygen and hydroperoxide) and organic (peroxo compounds) oxidants. Moreover, the main part of organic metastable oxidants is represented by peracetic acid, which is formed by oxidation of acetic acid with inorganic oxidants of ANK.

After the introduction of acetic acid and mixing it with the volume of ANK, "anolyte ALOKS" is ready for use in 3 minutes and retains its functional properties for 6 hours. After 6 hours, "anolyte ALOKS" is not recommended to be used, but after 24 hours the active ingredients of "anolyte ALOKS" are almost completely mutually neutralized. The antimicrobial activity of "anolyte ALOKS", confirmed by a number of foreign authoritative research centers, exceeds the analogous properties of ANK by 1000-10,000 times, which allows reducing the duration of treatment of products with this solution to 1-3 minutes. "Anolyte ALOKS" does not cause corrosion of metals when processed by immersion. It is highly effective under the conditions of high organic load [12.14].

Unipolar electrochemical activation (ECA) of a liquid is based on well-known electrolysis reactions. However the electrolysis of concentrated solutions ends in a clean finished product, and weak (up to $5 \mathrm{~g} / \mathrm{l}$ ) aqueous solutions of salts or ordinary drinking water, which in its composition contains up to $1 \mathrm{~g} / 1$ of various salts, are subjected to electrochemical activation. The purpose of ECA is to transfer the liquid to an activated state. It was found that ECA makes it possible to transform fresh or slightly salted water into a highly active technological solution with many functional properties without additional expenditure of chemical reagents $[8,9]$.

Metastable compounds obtained at STEL-ANKSUPER installation, the concentration of which in terms of active chlorine is $0.05 \%$, and the mineralization is not more than $0.9 \mathrm{~g} / 1$ are of practical interest. Active substances (AS) of "Anolyte ..." are represented by a mixture of highly active metastable (electrochemically activated) oxidants, where their mass fraction in terms of active chlorine is in total $0.05 \pm 0.005 \%$ (hypochlorous acid, chlorine dioxide, hydrogen peroxide, singlet oxygen ozone).

The products of this group are low-toxic, rather cheap, effective against all groups of resistance of microorganisms and are used under various trade names, both independently and in various compositions $[8,10]$. Due to its efficiency and low toxicity, the scope of application of ANK is very wide, it is intended for disinfection of premises, equipment, tools of slaughterhouses, containers, wastewater, protective clothing, vehicles and other objects [8].

The detergent agents "Anolyte..." is compatible with ionic additives (cationic, anionic), as well as with nonionic surfactants and soaps. ANK is used for the purposes of disinfection, pre-sterilization and cleaning in accordance with the guidelines developed by Institute of Disinfection of the Ministry of Health of the Russian Federation.

After the use, Anolyte agent completely decomposes into initial substances (water and salt). It does not accumulate in the external environment and does not create films on surfaces.

The analysis of the mechanisms of action of detergent agents is a prerequisite for the development and improvement of new disinfection modes. The resistance of pathogenic bacteria to the effects of detergent agents depends on the characteristics of the used chemical (concentration, duration of action, etc.), and to a large extent depends on the differences in the ultrastructural organization of gram-negative and grampositive bacteria. The method of transmission of electron microscopy allows studying the effect of products on certain structures of an isolated bacterial cell. The method of scanning electron microscopy allows assessing the effect of the detergent agent on the population of bacteria organized in microcolonies and colonies $(2,3)$.

\section{Materials and methods}

In our own studies, we used an original method that allows studying the kinetics of bacterial inactivation at the population level. This method is based on the determination of the number of colony-forming units (CFU) of microorganisms by the method of serial dilutions in semi-liquid agar with subsequent inoculation on membrane filters.

The research was carried out in the laboratory of sanitary microbiology of All-Russian Research Institute of Veterinary Sanitation, Hygiene and Ecology - a branch of All-Russian Research Institute of Experimental Veterinary Medicine named after K.I.Skryabin and Ya.R. Kovalenko of the Russian Academy of Sciences. Light microscopy using an AxioImager A1 optical microscope (Carl Zeiss, Germany) was carried out in Moscow State University of Food Production. Electron microscopy using scanning electron microscopes TM 4000 (Hitachi, Japan) and Vega || LMU (Tescan, Czech Republic) was carried out in the Russian State Center for Animal Feed and Drug Standardization and Quality.

A bacterial cell of a homogeneous population in the $\mathrm{S}$-form in the amount of $109 \mathrm{cell} / \mathrm{ml}$ was introduced into test tubes containing certain concentrations of the product. For control, a suspension of bacterial cells of the same population was used without the effect of a disinfectant. After the time of interaction of bacteria with the product, serial dilutions were prepared on the basis of isotonic sodium chloride solution or phosphate buffered saline ( $\mathrm{pH}$ 6.9-7.0). Dilutions drops were applied in the 
amount of $50 \mu \mathrm{l}$ onto membrane filters (pore diameter $0.15-0.25 \mu \mathrm{m})$ placed on the surface of a dense nutrient medium in Petri dishes.

They were thermostated under the conditions optimal for the studied species of bacteria for at least 5-8 days, since the growth of microorganisms can be slowed down as a result of exposure to unfavorable factors.

The developed method is simple to carry out. It is reproducible. It gives statistically reliable results and allows not only quantitative assessment of the effect of abiotic factors, but also a qualitative analysis of the processes occurring in the bacterial population without violating its architectonics.

Disinfectant "Anolyte ANK-SUPER", the installation to receive ECA solution "Anolyte ANK-SUPER" "STEL-ANK-SUPER-40" is produced by Delfin Aqua LLC. Characteristics of the ECA solution: Cox - 500 $\mathrm{mg} / \mathrm{l}(0.05 \%)$, total mineralization up to $0.9 \mathrm{~g} / \mathrm{1} ; \mathrm{pH}$ 6.0-6.5; ORP - $1000 \mathrm{~mW}$, sodium chloride conversion $99.9 \%$; the shelf life of the anolyte is 6 months if proper conditions are observed.

\section{Research results}

When the experiment expired, the growth of microorganisms at concentrations of $10^{4}-10^{2}$ was recorded in the control and when bacteria interacted with bactericidal concentrations of the product, there was no visible growth of microorganisms at concentrations of $10^{8}-10^{6}$. Subbactericidal concentrations of the products partially suppressed the growth of microorganisms at a concentration of $10^{8}-10^{7}$.

During the study of the ultrastructure of bacterial cells exposed to the anolyte, it was found that the drug caused significant destruction of the outer membrane of the cell wall, cytoplasmic membrane and ribosomes (Fig. 1). When the permeability barrier and the structure of the cytoplasmic membrane were violated, metabolites were released from the cells. Subbactericidal concentrations of the product, along with the nonviability of a part of the population, induced the process of cell heteromorphism with various manifestations of L-transformation. This results in the formation of spheroplasts or protoplasts of a round shape of various sizes, as well as unstable and stable L-shapes (Figure 2). This process is associated with partial or complete loss of the cell wall by bacteria, destruction of precursors for the synthesis of nucleic acids and enzymatic system.

The impact of the anolyte on S. aureus in the first minutes caused the increase in cells in volume, with further contact of the anolyte with bacterial cells, a local violation of the integrity of the cell wall, cytoplasmic membrane and ribosomes were observed (Figure 3).
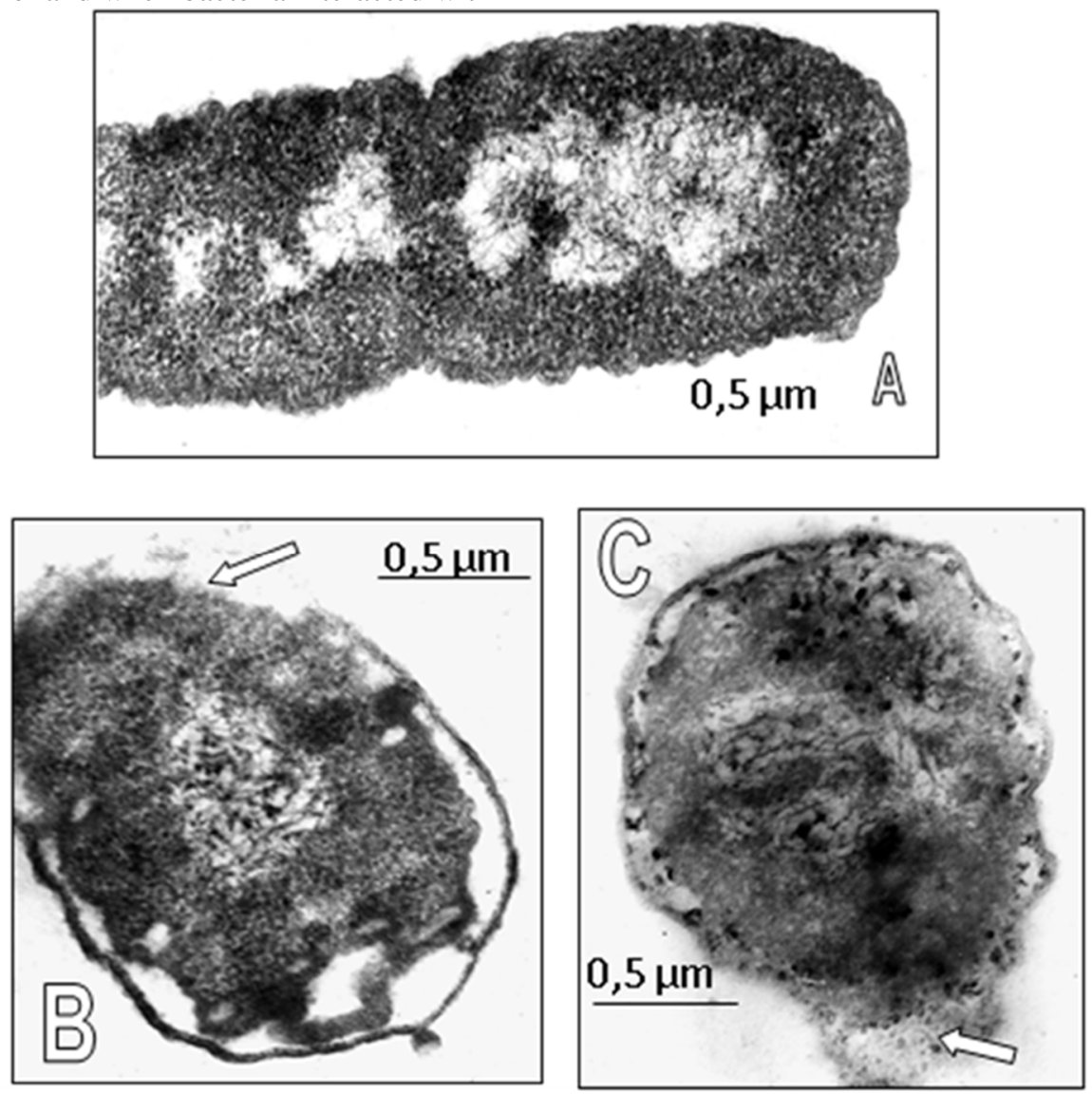

Figure 1. Effect of anolyte on cells of E.coli. A - control, B, C - ultrastructure of damaged cells; local damage to the cell wall and cytoplasmic membrane. TEM. 

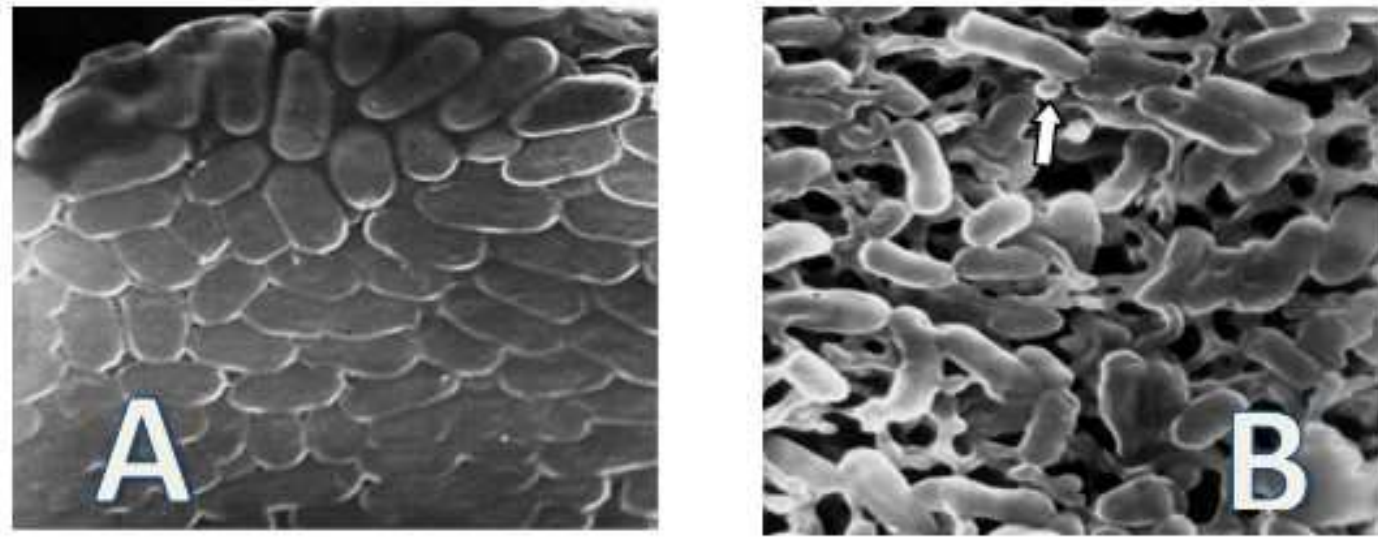

Figure 2. Effect of anolyte on E. coli cells. A - control. Fragment of E. coli colony in S-form. The cells are united by the intercellular matrix. B - heteromorphism and L-transformation in the population after exposure to anolyte. The cells are deformed, flattened, irregular in shape, with a disturbed division process, budding forms are found. SEM.

The performed studies made it possible to identify regular changes in the response of bacterial populations to the effect of anolyte. The changes occurring in the studied cultures of microorganisms were characterized by the death and transition of a part of the population to heteromorphic growth with the manifestation of Ltransformation. Anolyte destroyed the intercellular matrix and integuments on the surfaces of colonies in the

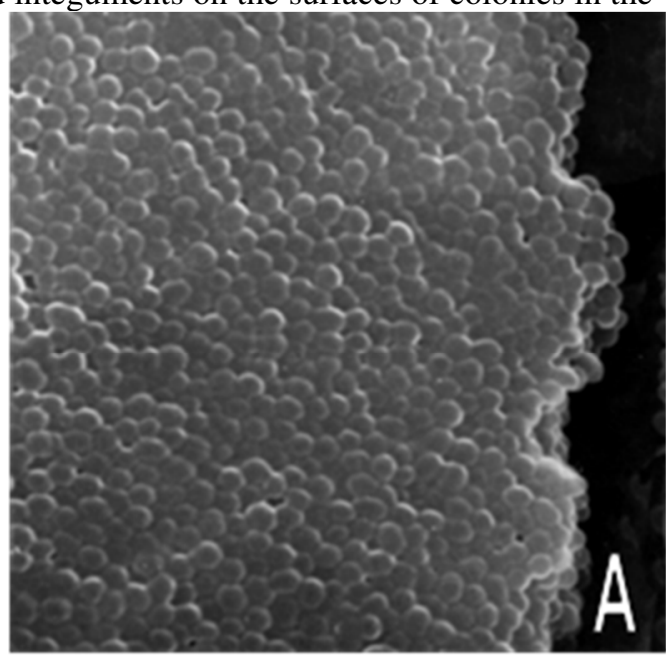

population, causing defective cell walls, as evidenced by the formation of cells of the protoplast and spheroplastic type, as well as other cells of altered morphology - small rounded L-shapes $0.3-0.5 \mu \mathrm{m}$ in size, united by sheaths, convoluted cells - revertants.

All morphologically altered cells with a defective cell wall lost their ability to adhere and colonize.

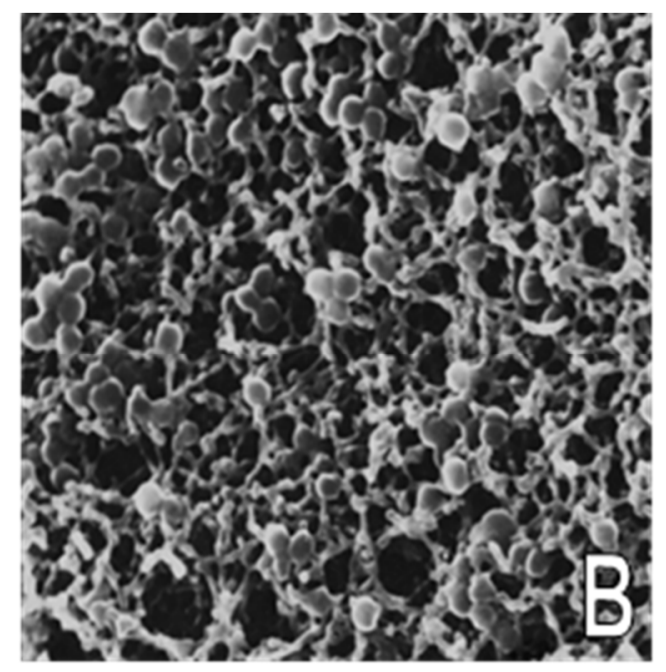

Figure 3. Fragments of S. aureus population: A - before exposure to anolyte (control); B - after exposure to anolyte. SEM.

\section{Conclusion}

Summing up the results of many years of research on the study of the effect of disinfectants on bacterial populations, we can state that the most effective antibacterial properties will have the products that cause the destruction of the surface structures of cells (capsule, extracellular substances - intercellular matrix, integument; cell wall, cytoplasmic membrane) and the agents that violate the structure of ribosomes and DNA. The natural response of the bacterial population to the action of abiotic factors is the destruction of the extracellular matrix and the covers in the colonies, the violation of the integrity of the cell walls, which leads to heteromorphism of cells with manifestations of Ltransformation and the formation of stable or unstable Lforms. The study of structural and functional changes in bacterial cells contributes to the purposeful creation of new antibacterial drugs, as well as the scientific substantiation of their use.

\section{References}

1. D. $\square$. $\square$ annikova, E. $\square$. Semenova, I. $\square$. Pavlova, $\square . \square$. Zakomyrdin, The effect of electrochemically activated solutions on the populations of some 
pathogenic bacteria (electron microscopic examination). First Communication, Problems of Veterinary Sanitation and Ecology, 115, 68-78 (2003)

2. I.B. Pavlova, Ecological aspects of the existence and development of populations of mycobacteria, Veterinary pathology, 1-2 (9), 65-68 (2004)

3. I.B. Pavlova, E.M. Lenchenko, D.A. Bannikova, Atlas of the morphology of the population of pathogenic bacteria (Kolos, Moscow, 2007)

4. P. Popov, Application of disinfectant "HyponatBPO" for the disinfection of slaughtering and livestock dressing workshops, IOP Conference Series: Earth and Environmental Science, 422(1), 012046 (2020)

5. P. Popov, The technology of using the disinfectant "Hyponate BPO" for disinfection of refrigerated chambers, BIO Web of Conferences, 17, 00181 (2020)

6. V.I. Dorozhkin, Determination of bactericidal and disinfecting action of the "Hyponate-BPO" against the vegetative microflora, IOP Conf. Series: Earth and Environmental Science, 640, 022052 (2021)

7. V.M. Bakhir, Modern technical electrochemical systems for disinfection, purification and activation of water (VNIIMT, Moscow, 1999) 84 p.
8. V.M. Bakhir, Spectrum of application possibilities of electrochemically activated anolytes from STEL devices of different modifications and generations, Medical Alphabet, 2, 42-48 (2010)

9. V.M. Bakhir, Method for producing electrochemically activated disinfectant solution and installation for its implementation: Patent for invention RUS 2329197 (September 29, 2006)

10. V.M. Bakhir, Electrochemical activation (VNIIIMT, Moscow, 1992) Part 2, 657 p.

11. V.M. Bakhir, Electrochemical activation in medicine, agriculture, industry, 3rd Intern. symposium. Reports and short communications (Moscow, 2001) 265 p.

12. V.M. Bakhir, Electrochemical activation: a universal tool for terrestrial chemistry (Marketing Support Services, Moscow, 2005) 176 p.

13. V.M. Bakhir, An electrolytic method of drinking water purification: Patent GB No. 2257982 (27 January 1993)

14. V.M. Bakhir, Apparatus for Electrochemical Treatment of Water: Patent USA No. 5427667 (27 June 1995)

15. V.M. Bakhir, V.P. Grishin, S.A. Panicheva, V.I. Toloknov, Evaluating the efficiency of electrochemically activated solution sterilization of medical instruments by computer-aided simulation of time course of nosocomial HIV infection, Medical equipment, 2, 14-16 (1999) 